\title{
Prenatal Starvation Retards Development of the Ventilatory Response to Hypoxia in Newborn Guinea Pigs
}

\author{
ANDREW J. LECHNER AND DEBRA S. TULL
}

Department of Physiology, St. Louis University School of Medicine, St. Louis, Missouri 63104

\begin{abstract}
Prenatal starvation causes pulmonary hypoplasia in newborn guinea pigs, and is associated with postnatal cyanosis, hypothermia, and respiratory failure. To determine the effects of such starvation on ventilation, neonates from litters either fed ad libitum throughout gestation (control) or given $\mathbf{5 0 \%}$ rations in the last trimester of pregnancy (starved) were studied at $29^{\circ} \mathrm{C}$ by plethysmography in 21,11 , and $5 \% \mathrm{O}_{2}$. After 15 min (steadystate) in $11 \%$ and then $5 \% \mathrm{O}_{2}, 13$ of 14 controls (mean = $95 \mathrm{~g})$ sustained increases in weight-specific minute ventilation of 46 and $75 \%$ compared to values in air $(p<0.01)$, due to increases in respiratory frequency. Seven of 11 starved neonates $($ mean $=76 \mathrm{~g})$ also sustained increases in respiratory frequency and weight-specific minute ventilation in 11 and $5 \% \mathrm{O}_{2}$ similar in magnitude to those of the normal controls, although at higher weight-specific tidal volumes. One abnormal control $(85 \mathrm{~g})$ and four starved neonates $($ mean $=70 \mathrm{~g}$ ) hyperventilated in air, did not respond to $11 \% \mathrm{O}_{2}$, and then hypoventilated in $5 \% \mathrm{O}_{2}$ due to a reduced weight-specific tidal volume. Neonates with normal ventilatory patterns did not alter weight-specific minute ventilation in $100 \% \mathrm{O}_{2}$ and did not show a biphasic response in acute (1-5 min) exposures to moderate hypoxia, as noted for newborn of other species. Thus, hypoxia identified those starved neonates in which pulmonary immaturity or other starvation-induced pathologies necessitated a maximal ventilatory effect in air. The sustainable hyperventilation among normal guinea pigs during hypoxia emphasizes the precocial development in this species at birth, which may be compromised by intrauterine starvation. (Pediatr Res 20: 920-924, 1986)
\end{abstract}

\section{Abbreviations}

$\dot{\mathrm{V}} \mathrm{O}_{2}$, oxygen consumption $(\mathrm{ml} / \mathrm{min})$

$\dot{\mathrm{V}}_{\mathrm{E}}$, weight-specific minute ventilation $(\mathrm{ml} / \mathrm{min} / 100 \mathrm{~g})$

$\mathrm{V}_{\mathrm{T}}$, weight-specific tidal volume $(\mathrm{ml} / 100 \mathrm{~g})$

f, respiratory frequency (per min)

$T_{T}$, total breath duration (s)

$T_{1}$, inspiratory duration (s)

$\mathrm{F}_{102}$, inspired oxygen concentration (\%)

$\mathbf{V}_{\mathrm{T}} / \mathbf{T}_{\mathrm{I}}$, mean inspiratory airflow $(\mathrm{ml} / \mathrm{s} / 100 \mathrm{~g})$

ANOVA, analysis of variance

Received March 10, 1986; accepted May 12, 1986.

Correspondence Dr. Andrew J. Lechner, Department of Physiology, St. Louis University School of Medicine, 1402 South Grand Boulevard, St. Louis, MO 63104.

This work was supported by the American Lung Association and by Grant HL 29640 from the National Heart, Lung, and Blood Institute.
Prenatal caloric restriction (starvation) severely retards pulmonary growth and development in guinea pigs, which are normally born with functionally mature lungs $(1,2)$. Starvation during the last trimester of pregnancy causes high perinatal mortality, pulmonary hypoplasia, reduced surfactant production, altered tissue elastic recoil, and decreased anatomical diffusing capacity (3-5). Many of the starved newborn guinea pigs are cyanotic and hypothermic, and subsequently die of apparent respiratory failure $(3,6)$. Similarities in survivorship as well as in lung structure and function between prenatally starved animals and human premature and small-for-date infants suggest that these animal studies are excellent models of such clinical conditions and their postnatal consequences (7-13).

In humans, the few reports concerning the effects of malnutrition on ventilatory control have been performed using normal adult volunteers (c.f. Ref. 14). Low birth weight infants show reduced $\dot{\mathrm{VO}}_{2}, \dot{\mathrm{V}}_{\mathrm{E}}$, and thermoregulatory ability (15-18), but ethical considerations preclude measurement of their ventilatory abilities beyond minimal levels. Thus the impact of prenatal malnutrition, while probably present to varying degrees, cannot be assessed despite its undisputed global importance to infant survival (19). Animal studies concerning the effects of prematurity on respiratory volumes and ventilatory control $(20,21)$ have focused only on normal interrupted gestations rather than intrauterine growth retardation such as occurs with prenatal starvation. This report represents the first description of ventilation immediately following the stress of prenatal starvation, in both normoxia and hypoxia. The results on respiratory impairment correlate with comprehensive pulmonary data recently presented elsewhere for this same animal model.

\section{MATERIALS AND METHODS}

Animals. Pregnant Hartley-strain guinea pigs with verified dates of insemination were obtained from Camm Research Institute (Wayne, $\mathrm{NJ}$ ) when 3 wk pregnant, individually caged at $22^{\circ} \mathrm{C}$, and provided water ad libitum. Control sows received food ad libitum (Guinea Pig Chow No. 5025, containing $18.5 \%$ protein, $4.0 \%$ fat, $11.0 \%$ fiber, and approximately $175 \%$ of known vitamin and mineral requirements, Ralston Purina Co., St. Louis, MO) throughout gestation. The experimental animals were fed ad libitum until day 45 of gestation, and then given $50 \%$ rations (Starvation) equal to $22 \mathrm{~g}$ of Chow per day during their last trimester (until about day 67 in both groups) (3-6).

Ventilation and metabolism measurements. $\mathrm{VO}_{2}$ and $\dot{\mathrm{V}}_{\mathrm{E}}$ were determined using whole-body plethysmography. Neonates were tested in one of two procedures within $12 \mathrm{~h}$ of birth and before ad libitum feeding of the mothers. In the first procedure (protocol A), animals were placed in the apparatus for 30-45 $\mathrm{min}$ to provide baseline resting data in $21 \% \mathrm{O}_{2}$ (air) of $\mathrm{VO}_{2}, \mathrm{~V}_{\mathrm{T}}, \mathrm{f}, \mathrm{T}_{\mathrm{T}}$, and $T_{1}$, using modified equations from Drorbaugh and Fenn (22) and Blake and Banchero (23). In this protocol, only steady-state 
ventilatory responses to hypoxic gases were measured. Following exposure to air, the chamber was purged with $11 \% \mathrm{O}_{2}, \dot{\mathrm{V}} \mathrm{O}_{2}$ was determined for $15 \mathrm{~min}$, and then $\mathrm{V}_{\mathrm{T}}, \mathrm{f}, \mathrm{T}_{\mathrm{T}}$, and $\mathrm{T}_{\mathrm{I}}$ measured for approximately $30 \mathrm{~s}$. The chamber was then purged with $5 \% \mathrm{O}_{2}$ and the procedure repeated. In St. Louis, these three levels of $\mathrm{F}_{\mathrm{IO} 2}(21,11$, and $5 \%)$ corresponded to ambient $\mathrm{PO}_{2} \mathrm{~S}$ of 158,82 , and $38 \mathrm{~mm} \mathrm{Hg}$ (ATPD).

Other neonates were examined at $29^{\circ} \mathrm{C}$ for their acute (1 through $5 \mathrm{~min}$ ) and steady-state (5 through $15 \mathrm{~min}$ ) ventilatory responses to varied $\mathrm{O}_{2}$ levels (protocol B). These animals breathed $21 \% \mathrm{O}_{2}$ for $20-30 \mathrm{~min}$, and then the chamber was purged with $100 \% \mathrm{O}_{2}$, with ventilation monitored continuously for $5 \mathrm{~min}$. The chamber was then refilled with $21 \% \mathrm{O}_{2}$ for 10 min, followed by stepwise exposures to 11 and $5 \% \mathrm{O}_{2}$ lasting 15 min each, with ventilation measured throughout. $\mathrm{No}_{\mathrm{VO}}$ measurements were made during these experiments.

The animal chamber was a 1.81 water-jacketed lucite cylinder regulated at $29.0 \pm 0.2^{\circ} \mathrm{C}$, a temperature within the thermoneutral zone for newborn guinea pigs in normoxia (Lechner AJ, unpublished results) (24). It was equipped with removable sensors for animal and chamber temperature (YSI thermistors, Yellow Springs, $\mathrm{OH}$ ), ambient $\mathrm{F}_{\mathrm{IO} 2}$ (Biomarine OMC 400, Devon, PA), and relative humidity (Digital Hygrometer, Cole-Parmer, Chicago, IL). Rigid side tubes provided leak, purge, and calibration injection ports, and access to a differential pressure transducer $\left(8 \mathrm{~T}-2, \pm 2 \mathrm{~cm} \mathrm{H}_{2} \mathrm{O}\right.$ full scale, $95 \%$ response time $<1 \mathrm{~ms}$, Medical Measurements Inc., Hackensack, NJ). Animals rested on a hardware cloth mat above indicator soda lime for $\mathrm{CO}_{2}$ absorption, which maintained chamber $\left[\mathrm{CO}_{2}\right]$ at less than $0.4 \%$. Relative humidity was maintained at $100 \%$ with water-saturated gauze. Oxygen concentrations in the chamber were changed by rapid purges of humidified gases from premixed calibrated cylinders in 30-60 s. Between purges, the chamber was sealed and consumed oxygen replaced from a spirometer modified to a sensitivity of $1.9 \mathrm{ml} \mathrm{O}_{2} / \mathrm{mm}$ bell displacement as previously described (25). The $\dot{\mathrm{VO}}_{2}$ was calculated from the spirometer kymograph as the average for the entire 15-min measurement without regard to minor fluctuations minute by minute (25). Other chamber parameters and ventilatory data were collected on a photographic chart recorder (E for M VR-6 Simultrace, White Plains, NY). Calibrations for $\mathrm{V}_{\Upsilon}$ indicated a reproducibility of $\pm 0.06 \mathrm{ml}$.

Values for $\dot{\mathrm{VO}}_{2}$ were converted to STPD conditions and ventilatory volumes expressed at BTPS. Data have been presented as means \pm standard errors, with significance determined by ANOVA. Because the normal ventilatory response to hypoxia had not been previously established in newborn guinea pigs, a preliminary ANOVA of the steady-state control data (protocol A above) was performed. In 13 of 14 controls, there were significant sustained increases in $\dot{\mathrm{V}}_{\mathrm{E}}$ after 15 -min exposure to 11 and $5 \% \mathrm{O}_{2}$. This was then defined as the normal response, regardless of whether the increased $\dot{V}_{E}$ occurred via $V_{T}$, $f$, or both. To compare normal controls, normal starved, and abnormal starved neonates, a modified ANOVA was performed at each level of $\mathrm{F}_{\mathrm{IO} 2}(3,26)$.

\section{RESULTS}

Protocol $A$. In 13 of 14 controls, $\dot{\mathrm{V}}_{\mathrm{E}}$ significantly increased ( $p$ $<0.01$ ) during $15 \mathrm{~min}$ of 11 and $5 \% \mathrm{O}_{2}$ due to sustained increases in $\mathrm{f}$ (Table 1, Fig. 1); 10 of 14 animals also increased $\mathrm{V}_{\mathrm{T}}$ while four showed no change or slight decreases. In 12 of 14 controls, both $\mathrm{T}_{\mathrm{I}}$ and $\mathrm{T}_{\mathrm{T}}$ also decreased $(p<0.05)$ as $\mathrm{F}_{\mathrm{IO} 2}$ was decreased from 21 to $5 \%$, although $\mathrm{T}_{\mathrm{I}} / \mathrm{T}_{\mathrm{T}}$ did not change (Table 1 ). Thus, $\mathrm{V}_{\mathrm{T}} / \mathrm{T}_{\mathrm{I}}$ increased $70 \%$ as $\mathrm{F}_{\mathrm{IO} 2}$ decreased from 21 to $5 \% \mathrm{O}_{2}(p<$ 0.01 , Fig. 1). Both resting $\mathrm{VO}_{2}$ and rectal temperatures (Tr) decreased significantly $(p<0.05)$ when $\mathrm{F}_{\mathrm{IO} 2}$ was reduced from 11 to $5 \%$ (Table 1). The single abnormal control $(85 \mathrm{~g})$ was characterized by high normoxic $\dot{\mathrm{V}}_{\mathrm{E}}$ and $\mathrm{V}_{\mathrm{T}}$, which did not change during exposure to $11 \% \mathrm{O}_{2}$ but declined during $15 \mathrm{~min}$ of $5 \%$ $\mathrm{O}_{2}$; values for $\mathrm{f}, \mathrm{T}_{1}$, and $\mathrm{T}_{\mathrm{T}}$ did not vary in this animal during

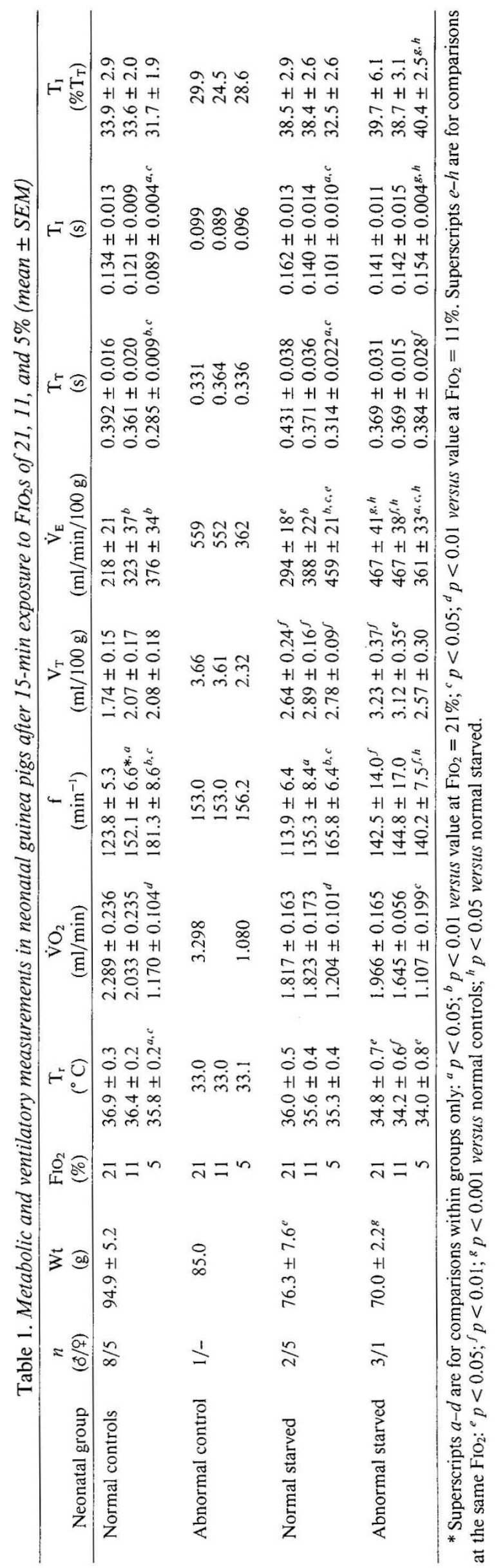



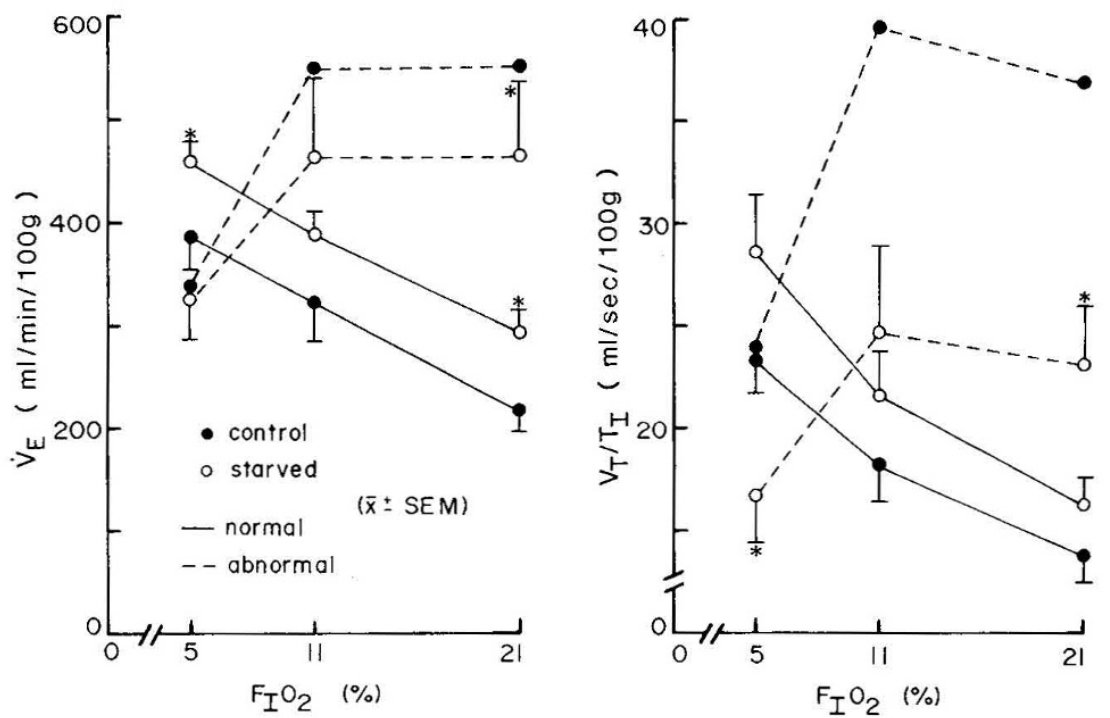

Fig. 1. Minute ventilation, $\dot{\mathrm{V}}_{\mathrm{E}}$, and mean inspiratory air flow, $\mathrm{V}_{\mathrm{T}} / \mathrm{T}_{\mathrm{I}}$, in newborn guinea pigs exposed to stepwise hypoxia (protocol A); data were collected after $15 \mathrm{~min}$ at each $\mathrm{F}_{1 \mathrm{OO} 2}$. Thirteen of 14 controls showed the normal pattern of sustained hyperventilation, as did seven of 11 neonates whose mothers were starved with $50 \%$ rations in their last trimester. Values for $\dot{V}_{E}$ and $V_{T} / T_{I}$ significantly increased for both normal starved and normal controls with decreasing $\mathrm{F}_{\mathrm{IO} 2}$ compared to values for each group in air $(p<0.01)$. The remaining four starved animals and a single control showed abnormally high $\dot{\mathrm{V}}_{\mathrm{E}}$ 's at $21 \% \mathrm{O}_{2}$, which did not increase at $11 \% \mathrm{O}_{2}$, and which declined at $5 \% \mathrm{O}_{2}$. See Table 1 for body weights and other details on these groups. ${ }^{*} p<0.05$ versus normal controls at the same $\mathrm{F}_{\mathrm{IO} 2}$.

hypoxia. This abnormal ventilatory pattern was not attributable to body weight since three smaller controls (weighing 63,73 , and $82 \mathrm{~g}$ ) showed the normal pattern as defined herein.

Although average gestational age at term (67.1 days) and litter size (4.0) were the same for control and starved litters, prenatal starvation resulted in a $22 \%$ decrease in body weight $(p<0.05)$ among liveborn neonates (Table 1). Seven starved neonates sustained hyperventilation during hypoxia and resembled normal controls with respect to body temperature at all $\mathrm{F}_{\mathrm{IO}_{2} \mathrm{~S}}$ and decreased $\mathrm{VO}_{2}$ in $5 \% \mathrm{O}_{2}$, although their average $\mathrm{V}_{\mathrm{T}} \mathrm{S}$ were larger at all levels of $\mathrm{F}_{\mathrm{IO} 2}$. All seven animals increased $\mathrm{f}$ during the reduction in $\mathrm{F}_{1 \mathrm{O} 2}$ from 21 to $5 \%$. Thus $\dot{\mathrm{V}}_{\mathrm{E}}$ also significantly increased with hypoxia $(p<0.01)$, and values were higher in the normal starved neonates than in controls at both 21 and $5 \% \mathrm{O}_{2}$ $(p<0.05$, Fig. 1). Six of the seven normal starved animals reduced both $T_{I}$ and $T_{T}$ during hypoxia, such that $V_{T} / T_{I}$ increased in a manner parallel to that seen in normal controls $(p$ $<0.01$, Fig. 1).

Four of the 11 starved neonates demonstrated an abnormal ventilatory response to hypoxia, which was a significantly higher rate of occurrence than in controls $\left(p<0.01\right.$ by the $\chi^{2}$ distribution). As noted for the single abnormal control, these four animals were similar in size to three starved neonates which demonstrated the normal ventilation pattern. In these animals, $\dot{\mathrm{V}}_{\mathrm{E}}$ in air was approximately twice that in normal controls $(p<$ 0.001 ) and did not increase further following $15 \mathrm{~min}$ in $11 \% \mathrm{O}_{2}$; subsequent exposure to $5 \% \mathrm{O}_{2}$ led to a pronounced decline in $\dot{\mathrm{V}}_{\mathrm{E}}(p<0.05$, Fig. 1). None of these animals altered $\mathrm{f}$ during hypoxia, and at $5 \% \mathrm{O}_{2}$, mean inspiratory airflow $\left(\mathrm{V}_{\mathrm{T}} / \mathrm{T}_{\mathrm{I}}\right)$ decreased significantly $(p<0.05)$. Although all neonates remained conscious throughout protocol A, the abnormal starved animals were cyanotic, hypothermic, and feeble by its conclusion (Table 1).

Protocol B. Six randomly-selected control neonates (mean = $104 \mathrm{~g}$ ) were studied for their acute ventilatory responses to $\mathrm{F}_{\mathrm{IO} 2}$ of $21,100,21,11$, and $5 \%$ (Fig. 2). Hyperoxia did not affect $\dot{V}_{E}$, $\mathrm{f}$, or other parameters compared to values in air, nor was ventilation altered by the subsequent return to $21 \% \mathrm{O}_{2}$. A $33 \%$ increase in $\dot{\mathrm{V}}_{\mathrm{E}}(p<0.05$ versus in air) occurred within $1 \mathrm{~min}$ of exposure to $11 \% \mathrm{O}_{2}$ due to both increased $\mathrm{V}_{\mathrm{T}}$ and $\mathrm{f}$; at $15 \mathrm{~min}$ this sustained increase in $\dot{\mathrm{V}}_{\mathrm{E}}$ was primarily due to the $27 \%$ increase in $\mathrm{f}$. When $\mathrm{F}_{\mathrm{IO} 2}$ was further reduced to $5 \%, \dot{\mathrm{V}}_{\mathrm{E}}$ increased within 2 min to $135 \%$ of the value in air via both $V_{T}$ and $f$; after 15 min $\dot{V}_{\mathrm{E}}$ was still $85 \%$ greater than in air $(p<0.01)$ due to the $70 \%$ elevation in f. All six controls were normal based on the criteria detailed above.

Among randomly selected starved neonates, five of six animals (mean $=81 \mathrm{~g}$ ) demonstrated a similar ventilatory pattern to that of the controls. Ventilation in these animals was unaffected by $100 \% \mathrm{O}_{2}$ and the subsequent return to air. Although the $32 \%$ increase in $\dot{\mathrm{V}}_{\mathrm{E}}$ in $11 \% \mathrm{O}_{2}(p<0.05$ versus in air) was sustained for $15 \mathrm{~min}$, this was due to a smaller relative increase in $f$ than in controls (Fig. 2). Reducing $\mathrm{F}_{\mathrm{IO} 2}$ to $5 \%$ caused a doubling of $\dot{\mathrm{V}}_{\mathrm{E}}$ compared to the air value within $2 \min (p<0.01)$, comprised of $40-50 \%$ increases in both $\mathrm{V}_{\mathrm{T}}$ and $\mathrm{f}$. After $15 \mathrm{~min}$ at $5 \% \mathrm{O}_{2}$, $\dot{\mathrm{V}}_{\mathrm{E}}$ was still $77 \%$ higher than in air $(p<0.01)$, due to elevations of 22 and $46 \%$ in $V_{T}$ and $f$, respectively ( $p<0.05$ for both). The sixth starved neonate $(61 \mathrm{~g})$ hyperventilated in air as described above for other abnormal animals. Exposure to $100 \% \mathrm{O}_{2}$ resulted in parallel fluctuations in $\mathrm{f}$ and $\dot{\mathrm{V}}_{\mathrm{E}}$, followed by a return to normoxic values (Fig. 2). Reducing $\mathrm{F}_{\mathrm{IO} 2}$ to $11 \%$ resulted in two periods of hyperventilation within the first $5 \mathrm{~min}$, associated with increases in $\mathrm{V}_{\mathrm{T}}$; within $15 \mathrm{~min}$ all ventilatory parameters had returned to normoxic levels. In $5 \% \mathrm{O}_{2}, \dot{\mathrm{V}}_{\mathrm{E}}$ rapidly increased and then decreased, reflecting changes in both $V_{T}$ and $f$, such that $f$ was substantially lower in this animal than the sustained $f$ levels for the 11 other neonates tested in this procedure.

\section{DISCUSSION}

Sustained hyperventilation during hypoxia has been considered a property of mature mammalian respiratory systems which develops in the weeks or months after normal birth. Except for newborn lambs, other neonates including premature and term infants show a biphasic response to hypoxia: $\dot{\mathrm{V}}_{\mathrm{E}}$ increases within 1-2 min of exposure but then declines to basal or lower levels under continued stress $(15,20,21,27-31)$. This response has been reported in resting, unsedated newborns using plethysmography or facial masks $(15,22,28)$ as well as in anesthetized, intubated animals in which more rapid response patterns to an ideal step reduction in $\mathrm{F}_{\mathrm{IO} 2}$ can be achieved $(20,21,29,30)$. Although the methodology used here obscured $\dot{V}_{E}$ changes during the $30-60$ s required to alter chamber $\mathrm{F}_{\mathrm{IO} 2}$, the plethysmography clearly documented persistent increases in $\dot{\mathrm{V}}_{\mathrm{E}}$ during hypoxia. 

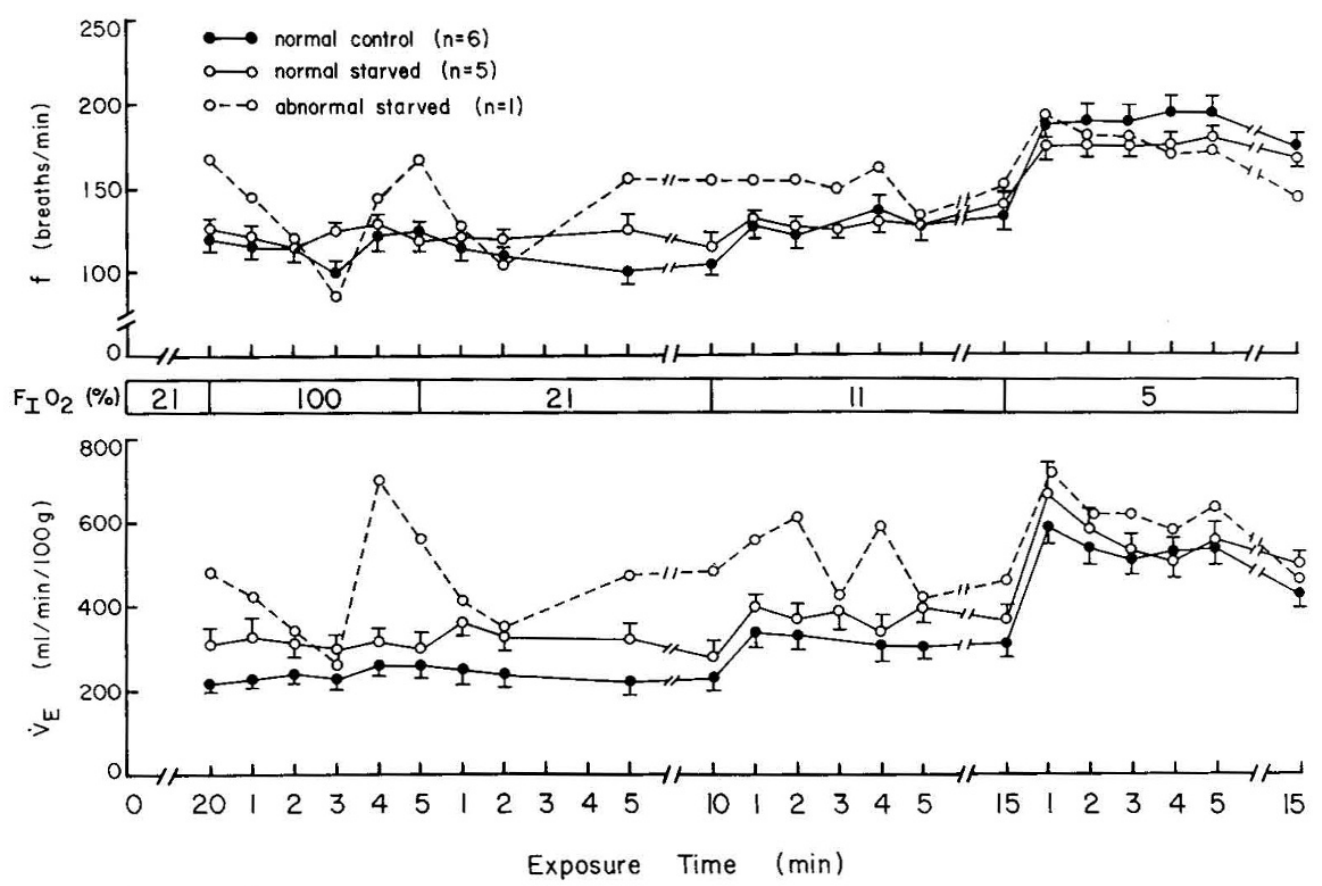

Fig. 2. Sequential changes in $\mathrm{f}$ and $\dot{\mathrm{V}}_{\mathrm{E}}$ among normal control (mean $=104.4 \pm 9.4 \mathrm{~g}$ ) and normal starved (mean $=81.8 \pm 12.1 \mathrm{~g}$ ) newborn guinea pigs exposed to $\mathrm{F}_{102}$ of $21,100,21,11$, and $5 \%$ for the times shown (protocol B). For both control and starved normal animals, acute increases in $\dot{\mathrm{V}}_{\mathrm{E}}$ occurring within $1-3 \mathrm{~min}\left(p<0.05\right.$ versus air) during $11 \% \mathrm{O}_{2}$ were sustained throughout exposure to that gas. Subsequent exposure to $5 \% \mathrm{O}_{2}$ led to large initial increases in $\dot{\mathrm{V}}_{\mathrm{E}}$ which declined slightly with time to values which were still significantly elevated at 15 min compared to $\dot{\mathrm{V}}_{\mathrm{E}}$ 's in $\operatorname{air}(p<0.01)$. An abnormal starved neonate $(61 \mathrm{~g})$ excessively hyperventilated in air, hypoventilated for several minutes in $100 \% \mathrm{O}_{2}$, but then reversed that decline while still in hyperoxia. Subsequent exposure to 11 and then $5 \% \mathrm{O}_{2}$ led to acute but unsustained increases in $\dot{\mathrm{V}}_{\mathrm{E}}$ while $\mathrm{f}$ in this animal did not differ in hypoxia from values in air. Values are means \pm SEM.

Considering the advanced appearance and function of the normal guinea pig lung at term (1-3), it is perhaps not surprising that the animal's ventilatory persistence in hypoxia is normally well developed at birth (Fig. 1).

The resting $\dot{\mathrm{VO}}_{2}$ and $\dot{\mathrm{V}}_{\mathrm{E}}$ reported herein for normal newborn controls in air agree well with predictions based on body weight, although $\mathrm{V}_{\mathrm{T}}$ and $\mathrm{V}_{\mathrm{T}} / \mathrm{T}_{\mathrm{I}}$ are slightly higher than reported by others $(24,32,33)$. The sustained increases in $\dot{V}_{\mathrm{E}}$ to 11 and $5 \% \mathrm{O}_{2}$ (Figs. 1 and 2) were larger than noted for adult guinea pigs, although those adults experienced a smaller change in inspired $\mathrm{PO}_{2}$ (about $38 \mathrm{~mm} \mathrm{Hg}$ ) in breathing 21 and then $15 \% \mathrm{O}_{2}$ at the altitude of Denver (32). Regardless of feeding regimen, many neonates which sustained normoxic $\mathrm{VO}_{2}$ in $11 \% \mathrm{O}_{2}$ did not do so in $5 \% \mathrm{O}_{2}$, and thus rectal temperature declined in many animals during this part of protocol A (Table 1). Although ventilatory parameters remained stable during this 15 -min period (Fig. 1, Table 1), it is possible that longer exposures to $5 \% \mathrm{O}_{2}$ would have eventually reduced ventilatory capacity.

Many of the starved guinea pigs also sustained changes in $\dot{V}_{E}$ during hypoxia, although their reliance on greater $\mathrm{V}_{\mathrm{T}} \mathrm{S}$ suggests some degree of respiratory impairment among even the normal starved group. More importantly, there was a significant increase in the percentage of abnormal animals following starvation, from $5 \%$ (one of 20 ) in controls to $30 \%$ (five of 17 ) among starved ( $p$ $<0.01$, both protocols). This altered percentage is consistent with the relative number of starved neonates whose lungs were severely retarded as measured by cellularity and anatomical diffusing capacity (3-5). Since low birth weight was a better predictor of pulmonary hypoplasia $(3,4)$ than of ventilatory abnormality (present study), other factors such as sex, litter size, or gestational length may also have influenced development of the abnormal ventilatory pattern.

All abnormal neonates were distinguished by their excessive hyperventilation in air which was usually accompanied by frank signs of cyanosis, hypothermia, and respiratory distress. Thus, if inadequate pulmonary development or other factors necessitated near-maximal ventilation in normoxic thermoneutrality, these animals may have been incapable of any additional ventilatory response to reduced $\mathrm{PO}_{2}$ or increased $\dot{\mathrm{VO}} \mathrm{O}_{2}$. In adults, ventilatory drive and respiratory muscle function are both compromised by malnutrition and reflect decreased respiratory muscle mass, glycogen stores, and muscle strength due to multiple myopathies $(14,34-36)$. In young animals, these effects of malnutrition on muscle performance would be in addition to any starvationinduced retardation of respiratory muscle development (37). Such impairment of the respiratory muscles is suggested by the frequency data among abnormal control and starved neonates: $\mathrm{f}$ is not only invariably high in 21 and $11 \% \mathrm{O}_{2}$, but peak values of $\mathrm{f}$ in $5 \% \mathrm{O}_{2}$ were always less than in normal animals (Table 1).

Normal control and starved guinea pigs sustained elevations of $\dot{\mathrm{V}}_{\mathrm{E}}$ in $11 \% \mathrm{O}_{2}$ (Fig. 2), an $\mathrm{F}_{\mathrm{IO} 2}$ at which the newborn of other species show a biphasic ventilatory pattern (27-31). The explanation for a biphasic response may be general immaturity of ventilatory control in other neonates, or specific effects of hypoxia such as depressed medullary activity, respiratory muscle fatigue, or altered lung and chest wall compliance $(15,20,21$, $28-31,33,36)$. Imposition of a stress such as starvation in these other animal models of neonatal respiration might clarify the mechanism involved.

\section{REFERENCES}

1. Lechner AJ, Banchero N, 1982 Advanced pulmonary development in newborn guinea pigs (Cavia porcellus). Am J Anat 163:236-246

2. Gaultier C, Harf A, Lorino AM, Atlan G 1984 Lung mechanics in growing guinea pigs. Respir Physiol 56:217-228

3. Lechner AJ 1985 Perinatal age determines the severity of retarded lung development induced by starvation. Am Rev Respir Dis 131:638-643

4. Lechner AJ 1985 Starvation-induced organ hypoplasia in prenatal and postnatal guinea pigs. Biol Neonate 48:36-42

5. Lechner AJ, Winston DC, Bauman JE 1986 Lung mechanics, cellularity, and surfactant after prenatal starvation in guinea pigs. J Appl Physiol 60:1610-1614

6. Lechner AJ 1984 Growth retardation and mortality in guinea pigs following perinatal starvation. Nutr Rep Int 30:1435-1447 
7. Curle DC, Adamson IYR 1978 Retarded development of neonatal rat lung by maternal malnutrition. J Histochem Cytochem 26:401-408

8. Faridy EE 1975 Effects of malnutrition on surface activity of fetal lungs. $J$ Appl Physiol 39:535-540

9. Frank L, Lewis PL, Garcia-Pons T 1985 Intrauterine growth-retarded rat pups show increased susceptibility to pulmonary $\mathrm{O}_{2}$ toxicity. Pediatr Res 19:281286

10. Naeye RL, Freeman RK, Blanc WA 1974 Nutrition, sex, and fetal lung maturation. Pediatr Res 8:200-204

11. Langston C, Kida K, Reed M, Thurlbeck WM 1984 Human lung growth in late gestation and in the neonate. Am Rev Respir Dis 128:607-613

12. Shapiro, McCormick MC, Starfield BH, Krischer JP, Bross D 1980 Relevance of correlates of infant deaths for significant morbidity at 1 year of age. Am J Obstet Gynecol 136:363-373

13. Hack M, Merkatz IR, Jones PK, Fanaroff AA 1980 Changing trends of neonatal and postneonatal deaths in very-low-birthweight infants. Am J Obstet Gynecol 137:797-800

14. Wilson DO, Rogers RM, Hoffman RM 1985 Nutrition and chronic lung disease. Am Rev Respir Dis 132:1347-1365

15. Cross KW, Oppe TE 1952 The effect of inhalation of high and low concentrations of oxygen on the respiration of the premature infant. J Physiol (Lond) 117:38-55

16. Silverman WA, Sinclair JC, Agate FJ Jr 1966 The oxygen cost of minor changes in heat balance of small newborn infants. Acta Paediatr Scand 55:294-300

17. Bhakoo ON, Scopes JW 1974 Minimal rates of oxygen consumption in smallfor-date babies during the first week of life. Arch Dis Child 49:583-585

18. Gudinchet F, Schutz Y, Micheli JL, Stettler E, Jequier E 1982 Metabolic cost of growth in very low-birthweight infants. Pediatr Res 16:1025-1030

19. World Health Organization 1971 Food fortification protein-calorie malnutrition. WHO technical report no. 477. World Health Organization, Geneva.

20. LaFramboise WA, Woodrum DE, Guthrie RD 1985 Influence of vagal activity on the neonatal ventilatory response to hypoxemia. Pediatr Res 19:903-907

21. LaFramboise, WA, Woodrum DE 1985 Elevated diaphragm electromyogram during neonatal hypoxic ventilatory depression. J Appl Physiol 59:10401045

22. Drorbaugh JE, Fenn WO 1955 A barometric method of measuring ventilation in newborn infants. Pediatrics 16:81-87

23. Blake CI, Banchero N 1985 Ventilation and oxygen consumption in the guinea pig. Respir Physiol 61:347-355

24. Zeisberger E, Bruck K 1967 Quantitative Beziehung Zwischen Noradrenalin Effect und Ausmass Der Zitterfreien Thermogenese Beim Meerschweinchen. Pflügers Arch 296:263-275

25. Lechner AJ 1977 Metabolic performance during hypoxia in native and acclimated pocket gophers. J Appl Physiol 43:965-970

26. Sokal RR, Rohlf FJ 1969 Biometry. WH Freeman Co, San Francisco.

27. Purves MJ 1966 The effects of hypoxia in the newborn lamb before and after denervation of the carotid chemoreceptors. J Physiol (Lond) 185:60-77

28. Rigatto H, Brady JP, Torre Verduzco R 1975 Chemoreceptor reflexes in preterm infants: I. The effect of gestational and postnatal age on the ventilatory response to inhalation of $100 \%$ and $15 \%$ oxygen. Pediatrics $44: 604$ 613

29. Lawson EE, Long WA 1983 Central origin of biphasic breathing pattern during hypoxia in newborns. $\mathrm{J}$ Appl Physiol 55:483-488

30. Blanco CE, Hanson MA, Johnson P, Rigatto H 1984 Breathing pattern of kittens during hypoxia. J Appl Physiol 56:12-17

31. Eden GJ, Hanson MA 1985 The effect of hypoxia from birth on the biphasic respiratory response of the newborn rat to acute hypoxia. J Physiol (Lond) 366:59P(abstr)

32. Blake CI, Banchero N 1985 Effects of cold and hypoxia on ventilation and oxygen consumption in awake guinea pigs. Respir Physiol 61:357-368

33. Mortola JP 1984 Breathing pattern in newborns. J Appl Physiol 56:1533-1540

34. Arora NS, Rochester DF 1982 Respiratory muscle strength and maximal voluntary ventilation in undernourished patients. Am Rev Respir Dis 126:5-

35. Kelsen SG, Ference M, Kapoor S 1985 Effects of prolonged undernutrition on structure and function of the diaphragm. J Appl Physiol 58:1354-1359

36. Muller N, Gulston G, Cade D, Whitton J, Froese AB, Bryan MH, Bryan AC 1979 Diaphragmatic muscle fatigue in the newborn. J Appl Physiol 46:688695

37. Maxwell LC, McCarter RJM, Kuehl TJ, Robotham JL 1983 Development of histochemical and functional properties of baboon respiratory muscles. J Appl Physiol 54:551-561 